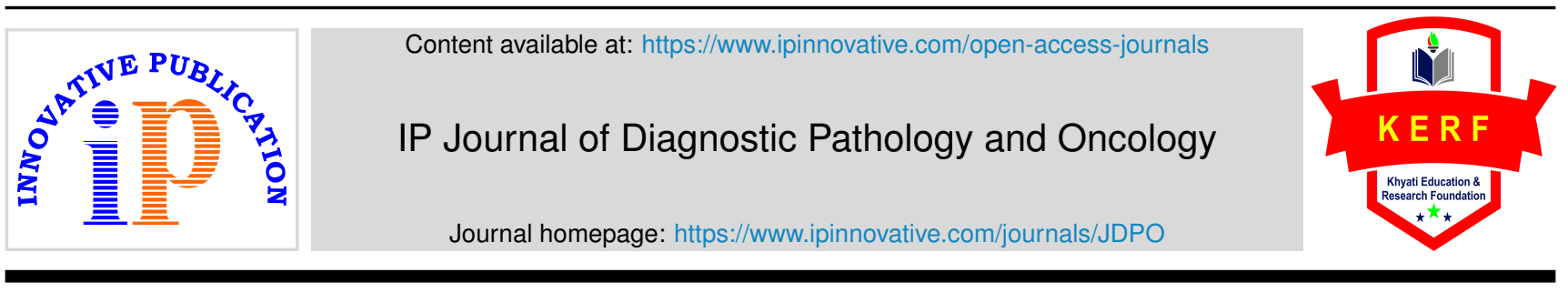

Original Research Article

\title{
Bethesda reporting of thyroid FNACS with T3, T4, TSH correlation in a medical college of North Karnataka
}

\author{
Lalitha Reddy G' ${ }^{1}$, Zeenath Begum ${ }^{1} *$, Asha Patil ${ }^{1}$ \\ ${ }^{1}$ Dept. of Pathology, Khaja Bandanawaz Institute of Medical Sciences, Gulbarga, Karnataka, India
}

\section{A R T I C L E I N F O}

\section{Article history:}

Received 07-10-2020

Accepted 28-10-2020

Available online 18-12-2020

\section{Keywords:}

Bethesda category

FNAC

Thyroid

lesions

T3

$\mathrm{T} 4$

TSH

\begin{abstract}
A B S T R A C T
Introduction: Fine needle aspiration cytology (FNAC) is a safe, cost effective and accurate means of evaluating thyroid lesions. Using The Bethesda system of reporting thyroid cytopathology (TBSRTC), cytopathologist can communicate thyroid FNA interpretations to the referring physician which is clinically useful.

Aim: To describe the cytomorphological features of FNAC and correlate with thyroid hormone status in patients presented with diffuse swelling/solitary nodule of thyroid.

Materials and Methods: A total of 50 cases of thyroid FNA s studied for 10 months duration from Dec 2019 to Sept 2020 in the Department of pathology, KBNIMS, Gulbarga. The lesions were evaluated cytologically, categorised according to the Bethesda system for reporting thyroid cytopathology and correlated with Thyroid hormone profile.

Results: Out of 50 cases of thyroid FNAs studied, Females were most commonly affected and most common age group affected was middle aged individuals (31-40yrs). Bethesda Category 2 benign lesions were most commonly present in our study. Benign follicular nodule was more common among non neoplastic lesions. Most of the benign and malignant lesions were euthyroid and hypothyroidism is seen in hashimoto thyroiditis in most cases.

Conclusion: FNAC is a simple and cost effective diagnostic modality for thyroid lesions with high specificity and accuracy. cytological analysis in conjunction with thyroid hormone profile, helps clinicians determine the course of therapy in effective management of patients with thyroid lesions.

(C) This is an open access article distributed under the terms of the Creative Commons Attribution License (https://creativecommons.org/licenses/by/4.0/) which permits unrestricted use, distribution, and reproduction in any medium, provided the original author and source are credited.
\end{abstract}

\section{Introduction}

Fine needle aspiration cytology (FNAC) is now generally accepted by endocrinologists and surgeons as a safe, cost effective and accurate means of evaluating thyroid lesions. Widespread use of FNA has reduced number of patients requiring surgery by more than $50 \%$. It has increased the yield of malignancy at thyroidectomy by 2-3 times and has decreased the overall cost of managing thyroid patients by more than $25 \%{ }^{1}$

The Bethesda system of reporting thyroid cytopathology established a uniform, tiered reporting system for thyroid specimens. Using The Bethesda system of reporting

\footnotetext{
* Corresponding author.

E-mail address: drzeenta@gmail.com (Z. Begum).
}

thyroid cytopathology (TBSRTC), cytopathologist can communicate thyroid FNA interpretations to the referring physician which is clinically useful. ${ }^{2}$

Thyroid gland is an endocrine organ. Histologically, it is composed of 20-40 dispersed follicles, lined by cuboidal to low columnar epithelum. Hypothalamus secretes Thyrotropin releasing hormone which stimulates release of TSH (Thyrotropin) from anterior pituitary. It stimulates thyroid growth and thyroid hormone synthesis. ${ }^{3}$

The thyroid is an important gland involved in the metabolism, growth, development, and maintenance of the internal environment. ${ }^{4,5}$ Thyroid dysfunction is very commonly encountered in clinical practice. TSH is considered the most important indicator for the evaluation of thyroid function. ${ }^{6}$ The reference range of Free T4 is 9-30 
$\mathrm{pmol} / \mathrm{L}$, and Free T3 range is 3.5 to $6.5 \mathrm{pmol} / \mathrm{L}$ and reference range of TSH concentration is 0.2 to $4.2 \mathrm{mU} / \mathrm{L}^{7}$

In the present study, Bethesda reporting was emphasised and Category III, IV, V, VI lesions were asked by physicians to correlate with thyroid profile for better management of the patients. T3, T4, TSH levels are assessed and clinically categorized as Euthyroid, Hypothyroid and Hyperthyroid.

\section{Objectives}

1. To assess hormone levels- (T3,T4,TSH) of thyroid lesions and correlate the cytological findings.

2. To categorise thyroid FNAs based on Bethesda system of reporting thyroid cytopathology.

\section{Materials and Methods}

It was a retrospective analysis of 50 cases of thyroid FNA $\mathrm{s}$ of 10 months duration from Dec 2019 to Sept 2020 in the Department of pathology, KBNIMS, Gulbarga. All the patients who presented with thyroid diffuse swelling /nodule, were assessed for T3, T4, TSH hormone levels. FNAC was done with 23 gauge needle following standard procedure under aseptic precautions. From the aspirates, one dry \& one wet smears were made and stained with Giemsa, H\&E, and PAP stains. Smears were evaluated by General pathologist and categorised according to The Bethesda system of reporting thyroid cytopathology. The Thyroid Function Test profile (T3,T4,TSH) was performed using Cobas E411 Electro Chemiluminescence immunometric assay method.(Roche diagnotics).Data was evaluated for thyroid lesions

\section{Results}

The study was carried out in 50 patients who presented with palpable thyroid lesions of which, 38 were females and 12 male [Table 1] for a period of 10 months duration. The age group in the study ranged from 20 years to 60 years. Most of the patients belonged to the age group ranged from 31-40 years.

\section{Discussion}

Fine-needle aspiration (FNA) is the first line investigation for thyroid lesions and provide useful diagnostic information for clinical management. It is helpful in categorisation of thyroid lesions following TBSRTC and minimise the need for surgery.

In our study, most of the lesions were observed in females, correlating with studies by CK Sang et al, Gupta $\mathrm{R}$ et al., and Rupam et al., have similar findings. ${ }^{8,9}$ Most lesions from our study were Benign of Bethesda categoryII showing similar findings as Shukla et al ${ }^{10}$ and Benign follicular nodule is the most common lesion comprising of colloid goitre, diagnosed based on presence of thin colloid
\& bare nuclei with few follicular cells. Nodular goitre showing thin colloid, hyperplastic follicular epithelial cells and bare nuclei, Adenomatous nodule, showing clusters and singly scattered follicular epithethelial cells in the background of thin colloid correlating with incidence of category II thyroid lesions by Mahar et al, Suman poudel et al and Sood et al. ${ }^{11,12}$ Cytologically, hurthle cells \& granulomas (Figure 1) were demonstrated in hashimoto thyroiditis, some of the cases showed multinucleate giant cells.

3 cases were categorised as Non diagnostic, 2 cases were categorised as Atypia of undetermined significance showing clusters of follicular cells, in microfollicles or threedimensional groups and with scant colloid and extensive but mild atypia, 3 cases were categorised as Follicular neoplasm showing high cellularity, hurthle cells (Figure 2), cell clusters in micro follicles and solid pattern are seen in some cases and devoid of colloid. Benign hurthle cells with eccentric nucleus and abundant eosinophilic cytoplasm surrounded by lymphocyte impingement was noted in Lymphocytic or Hashimoto's thyroiditis.(Figure 3).

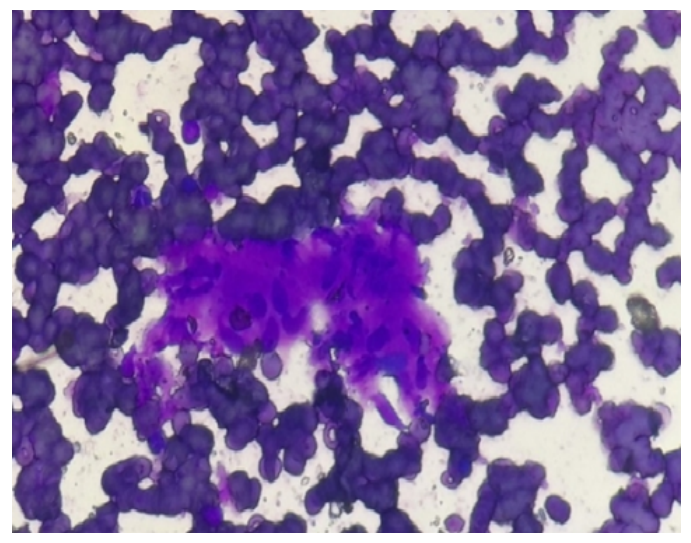

Fig. 1: Granuloma in Hashimato's thyroiditis (Field's 40X, HP)

Table 1: Age \& Sex Distribution of Thyroid Lesions

$\begin{array}{ccc}\text { Age } & \text { Male } & \text { Female } \\ 20-30 & 4 & 7 \\ 31-40 & 6 & 8 \\ 41-50 & 1 & 9 \\ 51-60 & 5 & 10 \\ \text {. of cases }=50 & 16 & 34\end{array}$

One case was suspicious for malignancy showing sparsely cellular, mild-to-moderate nuclear enlargement with mild nuclear atypia, nuclear grooving was evident, Intranuclear pseudo inclusions (INCIs) are very few and psammoma bodies are absent.

Neoplastic lesions were very few (3) in number, 2 cases comprising Papillary thyroid carcinoma was most common malignant lesion in our study showing same 
Table 2: Distribution of thyroid lesions

\section{Bethesda category of thyroid lesions}

Category-I : Non diagnostic/unsatisfactory

Category-II : Benign

Category- III : Atypia of undetermined significance

Category-IV : Follicular neoplasm/ suspicious for follicular neoplasm

Category-V : Suspicious for malignancy

Category- VI: Malignant
No. of Cases

3

33

2

3

1

3

(Table 2) FNAC revealed 3cases in Category I, 33 cases in benign i.e Category II, 3 cases each in Category IV and VI, 2 cases in Category III and one case in Category V.

Table 3: Bethesda correlation with thyroid function test

\begin{tabular}{lccc}
\hline Bethesda category & Euthyroid & Hypothyroidism & Hyperthyroidism \\
Category I Non diagnostic & 3 & - & - \\
Category II Benign- Follicularnodule & 9 & 24 & - \\
Hashimoto's Granulomatous & & 2 & - \\
Category III Atypia of undetermined & - & - & 2 \\
significance & & - & - \\
Category IV Follicular Neoplasm & 1 & 2 & - \\
Category V Suspicious for malignancy & 1 & \\
Category VI Malignancy & 1 & & \\
\hline
\end{tabular}

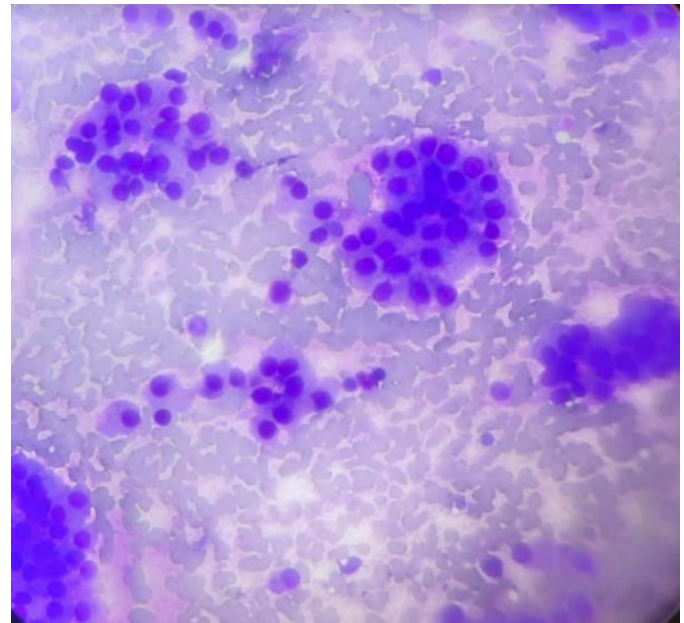

Fig. 2: Follicular neoplasm showing hurthle cells (H \& E, 10X, IP)

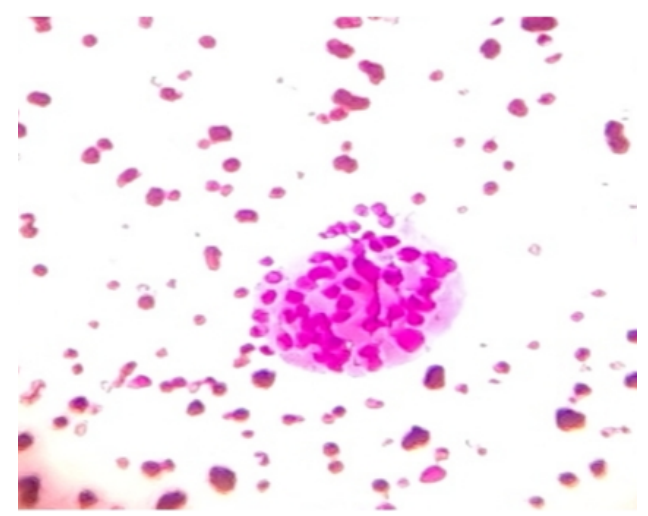

Fig. 3: Hashimoto's thyroiditis showing lymphocyte impingement (Field's, 40X, HP)

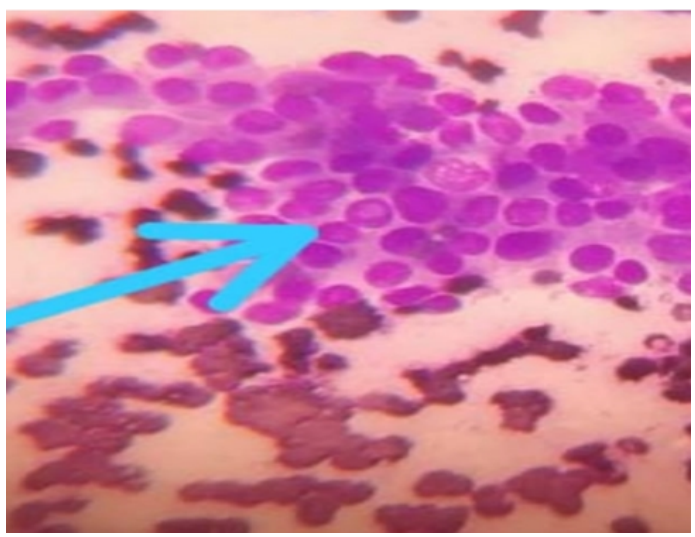

Fig. 4: Papillary carcinoma of thyroid showing intra cytoplasmic inclusion (Field's, 40X, HP)

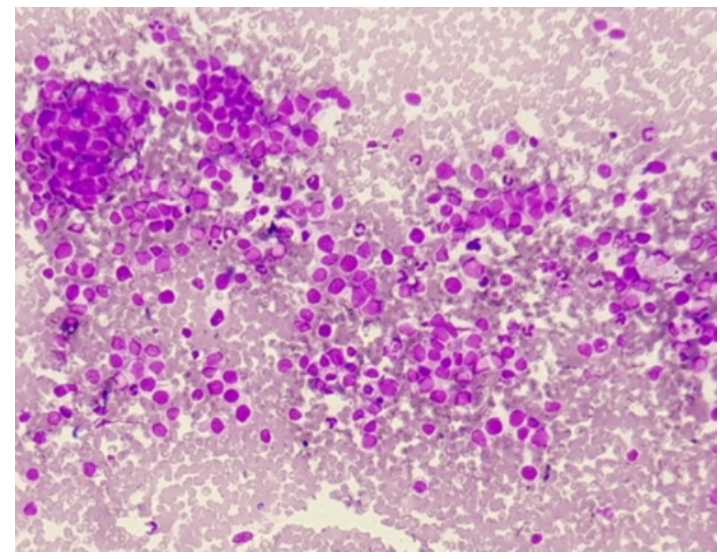

Fig. 5: Lymphoma in the background ofhashimoto's thyroiditis (Field's, 10X, IP) 


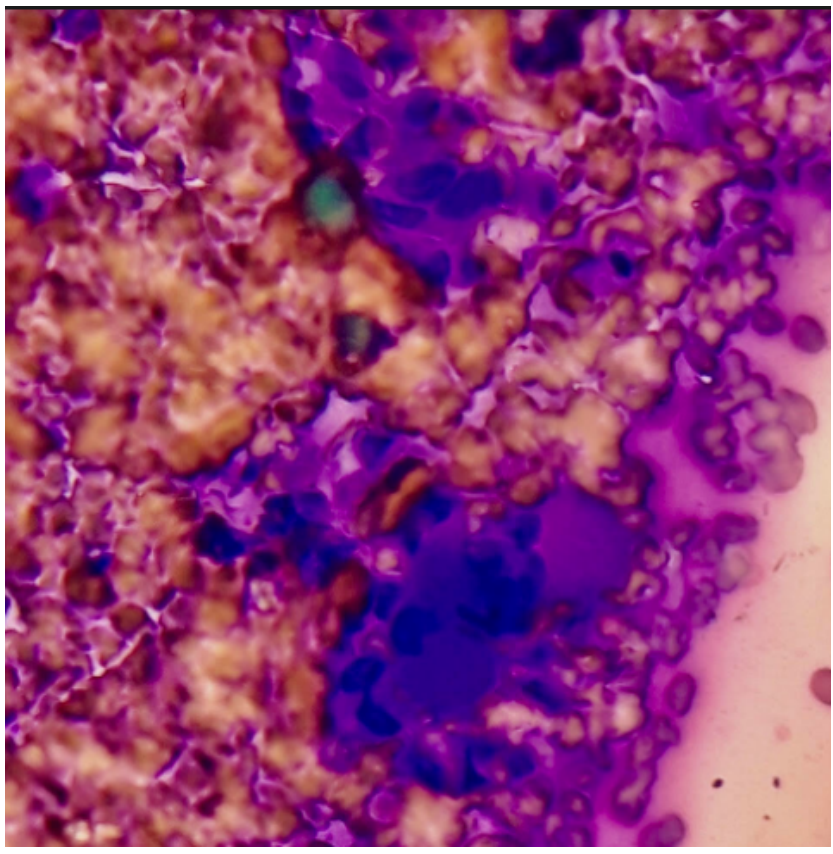

Fig. 6: Hurthle cell with clinging of lymphocytes (Field's 40X, $\mathrm{HP})$

findings in a study conducted by Sinna et al, ${ }^{13}$ Cells forming aggregates and sheets with scanty colloid. Optically clear pale nuclei, intra nuclear cytoplasmic inclusions and nuclear grooving was seen in papillary carcinoma of thyroid (Figure 4). One case was reported as lymphoma in the background of Hashimoto's thyroiditis (Figure 5) as studied by Usha et $\mathrm{al}^{14}$ showing mixed population of dispersed pleomorphic large lymphoid cells and few benign follicular epithelial cells with hurthle cell change in the background of lymphoid globules. The closest differential diagnosis includes anaplastic carcinoma of the thyroid gland that show cell clustering and nuclear molding and absence of lymphoglandular bodies. ${ }^{15,16}$

Estimation of thyroid hormonal status helps the clinician in proper management of such patients. Most of the thyroid lesions that are of Bethesda category II in our study are i.e; Benign Follicular nodule and they are Euthyroid status showing similar findings as stated by Junu et al. ${ }^{17}$ Hashimoto's thyroiditis presents as painless thyromegaly in middle aged woman. In most of the cases, it progresses over a period of time to subclinical and then clinically overt hypothyroidism. However, in some cases, it may be preceded by a transient hyperthyroid state (hashitoxicosis) due to destruction of follicles and subsequent rise in the free T3 and T4 along with fall in TSH and diminished radioactive iodine uptake. ${ }^{18}$

Hypothyroidism was seen in cases of lymphocytic thyroiditis, correlating with study by Minnu Prasannan et al. ${ }^{19}$ and benign follicular nodule. Cases of colloid goitre was showing euthyroid status. Hypothyroidism at the time of diagnosis is documented in $30-40 \%$ of patients due to replacement of the thyroid parenchyma by the lymphomatous process or due to underlying Hashimoto's Thyroiditis. ${ }^{16}$

Patients are unble to undergo all diagnostic tests owing to economical and social reasons. The loss to follow up of patients referred from surrounding areas as well as the fact that most of the lesions do not require surgical intervention, also limits the number of cases wherein histopathological correlation is available. Our cases has underwent a thyroid scan or antibody panel analysis. However, in spite of the limited resources we had a high satisfactory rate of smears and FNAC proved to be a sensitive and specific diagnostic modality.

\section{Source of Funding}

No financial support was received for the work within this manuscript.

\section{Conflict of Interest}

The authors declare they have no conflict of interest.

\section{References}

1. Clark DP. Thyroid cytopathology; 2010. p. 2-3.

2. The Bethesda system for reporting Thyroid Cytopathology ; 2018. p. $1-2$.

3. Siddegowda MS. Cytomorphological assessment and thyroid function analysis-A Dual approach to thyroid lesions. National J Lab Med. 2016;5(3):16-21.

4. Danzi S, Klein I. Thyroid Hormone and the Cardiovascular System. Med Clin North Am. 2012;96(2):257-68. doi:10.1016/j.mcna.2012.01.006

5. Yazbeck CF, Sullivan SD. Thyroid Disorders During Pregnancy. Med Clin North Am. 2012;96(2):235-56. [01:10.1016/].mcna.2012.01.004

6. Castellano CA, Laurin D, Marie-France L, Fortier M, Tessier D, Gaudreau P, et al. Thyroid function and cognition in the euthyroid elderly: A case-control study embedded in Quebec longitudinal study - NuAge. Psychoneuroendocrinology. 2013;38(9):1772-6. doi:10.1016/1.psyneuen.2013.02.013,

7. William's textbook of endocrinology; 2020. p. 356-7.

8. Sang CK, Sekadde-Kigondu C, Muchiri L. Fine needle aspiration cytology of thyroid nodules at Kenyatta National Hospital, Nairobi. East Afr Med J. 2008;84(3):117-20. 001:10.4314/eamj.v8413.9513.

9. Gupta M, Gupta S, Gupta VB. Correlation of fine needle aspiration cytology with histopathology in the diagnosis of solitary thyroid nodule. J Thyroid Res. 2010;18:37-40.

10. Shukla S, Tiwari SK. Clinicopathological evaluation of thyroid swelling in patient attending Hamidia Hospital Bhopal. Int Surg J. 2020;7:2222-5.

11. Mahar SA, Husain A, Islam N. Fine needle aspiration cytology of thyroid nodule: diagnostic accuracy and pitfalls. J Ayub Med Coll. 2006;18(4):26-9.

12. Sood N, Nigam JS. Correlation of Fine Needle Aspiration Cytology Findings with Thyroid Function Test in Cases of Lymphocytic Thyroiditis. J Thyr Res. 2014;2014:1-5. 101:10/155/2014/4305/0

13. Alshaikh S, Harb Z, Aljufairi E, Almahari SA. Classification of thyroid fine-needle aspiration cytology into Bethesda categories: An institutional experience and review of the literature. Cyto J. 2018;15:4 do1:10.4103/cytojournal.cytojournal_32_17.

14. Usha M, Kamath S, Sridhar M, Soman S. Primary thyroid lymphoma in the background of Hashimoto thyroiditis. Clin Cancer Investig J. 
2015;4:362-4.

15. Vigliar E, Caleo A, Vitale M, Crescenzo VD, Garzi A, Zeppa P, et al. Early cytological diagnosis of extranodal stage I, primary thyroid NonHodgkin lymphoma in elderly patients. Report of two cases and review of the literature. BMC Surg. 2013;13(2):S49. 10i:10.186/471-2482I3-S2-S49.

16. Amonkar G, Jashnani K, Shet T, Naik L, Rege J. Diagnostic fine needle aspiration cytology of primary thyroid lymphoma. J Cytol. 2007;24(3):140-1. 10i:10.4103/0970-9371.41905

17. Devi J, Aziz N. Cytomorphological evaluation and thyroid function [13]test analysis in various thyroid diseases - our experience at tertiary care centre. Int J Med Sci Clin Inventions. 2014;1(8):387-92.

18. Maitra A. Endocrine system. In: V K, AK A, [14]N F, JC A, editors. Robbins and Cotran Pathologic Basis of Disease. Elsevier; 2014. p. $1090-2$.

19. Prasannan M, Kumar SA. Hashimoto's thyroiditis-a cytomorphological study with serological correlation. IJSAR.
$2015 ; 2(8): 47-52$.

\section{Author biography}

Lalitha Reddy G, Post Graduate

Zeenath Begum, Professor and HOD

Asha Patil, Assistant Professor

Cite this article: Reddy G L, Begum Z, Patil A. Bethesda reporting of thyroid FNACS with T3, T4, TSH correlation in a medical college of North Karnataka. IP J Diagn Pathol Oncol 2020;5(4):405-409. 